\title{
Problem Training in Bilingual Education
}

\author{
Elena Meshcheryakova ${ }^{1 *}$, Elena Loktyshina ${ }^{2}$, and Julia Meshcheryakova ${ }^{1}$ \\ ${ }^{1}$ Volgograd State Social Pedagogical University, English Language Theory Department, 400066 Lenin Av. 27, Volgograd, Russia \\ ${ }^{2}$ Volgograd State Social Pedagogical University, English Language Teaching Methodology Department, 400066 Lenin Av. 27, \\ Volgograd, Russia
}

\begin{abstract}
The article deals with the problem of bilingual education in professional training. The authors considered the bilingual notion and its development by various scholars, its social and cultural foreground in the local region. The set of competencies including bilingual communicative competence used in the bilingual education process is regarded. The popular teaching approach in the bilingual education is seen as a problem-based learning which states new requirements for constructing mono and dialogic interactions. The authors reveal the theoretical aspects of problem-based learning and describe particular training techniques for language skills for Bachelor students in the process of teacher training bilingual education.
\end{abstract}

\section{Introduction}

Every year, school and university graduates face high demands on the part of the employer, society and the state as a whole. Such measures are necessitated by the transition of Russian education to the international level. According to the Russian Federation State Program "Development of Education" for 2013-2020, the new task for the domestic vocational education system is to provide graduates with professional and basic social and cultural competencies and facilities, including organization of teamwork, intercultural communication [1]. To fulfill the task, the state makes the educational process develop basic competencies for students.

The problem of bilingualism is still actual, contradictory phenomenon, facilitated by strict territorial boundaries and the desire to standardize the language of public education and administrative management [2].

\subsection{Genesis of the problem}

Researchers study bilingualism in different directions. In pedagogy, A.V. Timofeev created a bilingual model of vocational training for ESL teachers [3], N.E. Sorochkina examines the integral model of bilingual education in Russian school [4], G.N. Chirsheva studies the vocabulary assimilation by bilingual students [5], V.F. Gabdulkhakov deals with school students' multilingual competency [6], N.V. Kaguy - bilingual education process for preschool children through multicultural education [7], etc.

Various aspects of bilingualism are regarded from the different points of view: the phonetic aspects of bilingualism; a comparative-historical study of bilingualism in literature; language changes in bilingual speech; languages interference problems in individual speech; socio-cultural causes for bilingual communicative communication errors in polyethnic educational space, etc. The fact indicating this problem in demand now shows that there are increasing numbers of students working on bilingual studies in the field of teaching English.

\section{The Bilingualism Notion}

The term "bilingualism" comes from French (bilinguisme). Also, the term "bigloth" was widely used, but was soon replaced by "bilingual".

Beginners often rely on different opinions in defining the bilingualism concept, most often on the notion that bilingualism is "free two languages speaking" [8], or G.S. Ter-Minasova, who understands bilingualism as the communication between representatives of different cultures [9]. We believe that these concepts of bilingualism are not mutually exclusive.

All the above definitions are correct and at the same time somewhat contradictory. What does "fairly frequent real use" mean [10] in the two languages communication? This is when a person speaks two languages in the family or he or she speaks one language in the family and the other in society. In the case, when people who know the second language, but do not use it really often, cannot be called bilinguals. What does "equal knowledge of two languages" mean? Is there any proof that anyway a person is able to speak one language better than another language?

According to the analysis of the above definitions of scientists, our notion of bilingualism is the ability to speak two different languages in varying degrees, the skill to use languages in different capacity depending on the socio-cultural situation. The level to be ready to carry 
out bilingual communication defines the degree, scope of knowledge and, accordingly, necessary skills.

Following a number of researchers [11], our opinion is that it is inappropriate to develop a communicative competence for students that do not use the communicative competencies of the native language, which in turn affects the communicative competence development that is foreign speaking. These two processes are inseparable, are interrelated, therefore we consider the bilingual communicative competence formation more reasonable. It is through the use of two languages as a means of educational activity that the general communicative potential of the students expands and increases, their cognitive interest develops, their personal space is enriched and expanded, and their personal growth takes place, their world outlook deepens, new world pictures are formed, their personal space deeper penetrates into the global world sociocultural space.

\section{Biligual Education}

In our study, under bilingual education, we mean educational programs in which native and foreign languages act as the tools of education and selfeducation in the subjects study, and the content of which includes an international aspect that facilitates the educational process for intercultural cooperation in various activity in multilingual world.

At present, immersion (immersive) bilingual instruction is mainly used in Russia. It is aimed at enriching the communicative and speech practice and the achievement of the result level of productive bilingualism, the basic bilingual competence as an integrative unity of components and the necessary competences [12]. Subject competence includes knowledge and skills relating to the bilingual discipline itself; foreign communicative competence - foreign language knowledge, foreign language speaking skills, the foreign language ability to interact and cooperate; bilingual educational and cognitive competence independent cognitive and practical activities in native and foreign languages; the competence of personal selfimprovement - knowledge, ability and self-development ability, emotional self-regulation and self-support, including, in the teaching process and practical foreign language activities.

It is now very traditional to consider some competencies through the formation of others. And this is completely justified, since they are mutually reinforcing each other. For example, the skills of different types of second language activity. In particular, we can consider bilingual communicative competence through the following competences [13]:

1) integrative linguistic competence involving the assimilation of vocabulary, grammar, phonetics, the integrative bilingual skills mastery (the ability not only to read and understand what is read, but also to transmit it into another language);

2) intercultural competence, which is determined by the totality of such skills, how to solve professionally- directed tasks in socio-cultural situations in real interaction, modeling the conditions of intercultural communication with partners in the social sphere; to be aware of the national and cultural specifics; to master informal and formal styles of speech behavior;

3) bilingual discursive competence, which is determined by the ability to understand different forms of statements and build logical, correctly connected statements, using various functional styles that have both integrity and clear composition, the ability to switch from one language to another if necessary;

4) strategic competence, consisting in the ability to use a variety of strategies for maintaining communication when solving professional problems in the socio-cultural sphere of communication: a) attract the attention of the interlocutor; b) offer him the communication topic; c) initiate interaction; d) keep the respondent's attention; e) support the conversation and, as a result, complete the communication;

5) pragmatic competence, consisting in the ability to implement communicative intent; giving an emotional coloring to the utterance and expressing an assessment of the situation of monological or dialogical interaction (emotional-affective approach); taking into account the context of communication, its socio-cultural situation; the ability to influence the interlocutor; expressing gratitude [14] and using politeness strategies in social interaction [15-16].

However, as the practice of teaching foreign languages shows, the socio-cultural space in our region creates other problems that require solving problems in this activity area. At the Institute of Foreign Languages, the number of students who speak various languages as the first language (mother tongue) is increasing. This situation is becoming more typical, as more than 130 nationalities live in the Volgograd region. Undoubtedly, the teacher cannot always choose teaching technologies based on the use of the native language, and relies on approaches that exclude the use of the native language, for example, intensive approach, etc. In a number of schools in the city, students are taught simultaneously to two languages. Almost all students at the Institute of Foreign Languages specialize in two languages.

\section{Methodology}

Accordingly, students, faced with an increasing number of bilingualism in reality, are progressively more choosing this problem for their own research projects. As a means to solve this problem, they most often select the approaches that are relevant at the current time: ICT [17], communicative competence [18-19], socio-cultural, problematic, project method [20-22] and a number of others that are becoming increasingly popular in vocational education. In the framework of this article, we will focus on problem-based learning.

This direction is becoming gradually more popular in the process of teaching different subjects including teaching foreign languages. It is happening despite the fact that there is a contradiction between the relevance of the problem approach at present, its undoubted 
effectiveness and the inability of teachers to use foreign language in practice.

As an illustration, one should cite the fact that there are cases when part-time students refuse to use this approach as a methodological support in their diploma paper, thus motivating: "I do not like problems and I am afraid of problems and, therefore, I will not use the problematic approach in the theoretical proof." This shows that future teachers do not even have a weak understanding of the problem training, its capabilities in the process of foreign languages teaching, their knowledge is understood as purely empirical in nature and not methodical. This also indicates insufficient knowledge of basic sciences, philosophy, psychology, pedagogy, logic, etc.

In our opinion, the theory of problem-based learning enjoys too little attention among students engaged in the theory and methodology of teaching foreign languages. We rarely see that students rely on this approach when writing scientific works on technologies for teaching foreign languages.

If we turn to didactics, we will see that problem training primarily involves the use of problem situations, by which the psychological model of the conditions of generation of thinking is understood on the situational emerging cognitive need. Problem situations contain contradictions that do not have an unambiguous solution to the relationship of circumstances and conditions in which the activities of the individual or group are unfolding.

The basis for this is the general understanding of the problem. It comes from the Greek meaning the question, the riddle, which is proposed for solving, for a scientific solution; a task for finding the unknown. In the broad sense of the word, "problematic" also means a theoretical or practical question requiring study, solution; in science - a contradictory situation, acting in the form of opposing positions in the explanation of any phenomena, objects, processes and requiring an adequate theory for its solution. An important prerequisite for the successful solution of the problem is its correct formulation. An incorrectly posed problem or pseudoproblem is taken away from the resolution of genuine problems.

Considering the theory of problematic teaching, scientists are increasingly turning to R.S. Rubinstein in pedagogy, psychology, and methods of teaching the subject. Despite the fact that his statement has been for many years, it determines the very precise meaning of problem-based learning: "Thinking usually starts with a problem or question, with surprise or bewilderment, with a contradiction. This problem situation determines the involvement of the individual in the thinking process ... "[23].

In the case of foreign languages, these are new requirements for constructing dialogic interactions that require partners to discuss the problem, arguments, talk about a number of issues on a single issue, and create a unified opinion at the end of the dialogue.

However, when we address the problem of approaches, directions, methods of foreign languages teaching in the works of leading scientific methodologists, for example, Gal'skova, E.N. Solovova, A.N. Shchukin [24], we see that among other current approaches, or when considering any other approaches in the history of foreign languages teaching methodology, problematic training is not given due attention. How to explain this fact?

We assume that the method of problem training is an important part of any method or approach that it has not traditionally been singled out as a separate phenomenon.

In fact it should be just the other way. There are very good reasons for this. Let's turn to final exam for secondary school students. In particular, the requirements imposed on the skills in mono and dialogical utterance. If we turn to the criteria for evaluating the mono and dialogical statements for school graduates, then we see the leading place of the three tasks is the statement on the problem.

A student gets cards, which are presented with three tasks for the speaking answer - statement on the problem, dialogue on the situation, situation assessment. It checks the level of the student's competence: be active and polite, come up with ideas, give reasons, agree or disagree with your friend, invite your friend to suggest ideas, find out your friend's attitudes and consider them. According to the declared competences, the teacher has clear criteria fixed in the card of the examiner.

The student also needs a personal vision of the problem and some rethinking, for example, "You and your friend are discussing different opportunities for going away for a summer holiday". And traditionally, three areas of discussion are given, for example, in this case - "Seaside", "Mountain resort", "Camping", "Sightseeing tour".

In this case, students prepare a mini-project, the main components of which are: initiate and maintain conversation; come up with suggestion; give good reasons, invite the therapist, his partner, his partner's opinion.

But there are still a number of problems that we are highlighting, which impede the effective teaching a foreign language and slow down full-fledged interaction in problem-based learning:

- The trainees are embarrassed to speak a foreign language, are afraid to make mistakes and thus subject themselves to criticism from the teacher and other students. The trainee has nothing to say on the issue under discussion, they do not have enough information on this issue and in their native language.

- Learners do not understand the speech task, and therefore, what to do.

- Trainees do not have enough linguistic and speech tools to solve the task.

- When one student speaks, the others are silent, which means there is a danger of excluding them from the teaching communication, inefficient use of the lesson time.

- For paired and group forms, trainees often switch to the use of their native language and make many mistakes [24].

At the present time within the problematic training framework based on the following priority approaches: personal developmental, communicative, cooperative 
learning, remote, socio-cultural, it is important to draw attention to methodology within the problem-based learning, taking into account the language influence means. In this direction, scientists abroad have created a number of language teaching methods based on psychology: the method of "community" or the method of "community language learning (CLL) / Counseling learning" which involves discussion and solution of problems in persuasion process.

\section{Results}

To apply the proposed method, let's take the academic discipline "Practical course of the first foreign language" for language students. It is the core preparation for a language teacher and aims to form general cultural, general professional and special competencies. The discipline prepares bilingual bachelors for second language interaction using speech, linguistic, sociolinguistic and practical competences as components of other more general competences. The study program forms the ability and real readiness to implement a fullfledged communication by means English, as well as general competences, including declarative knowledge, existential competence, and cognitive abilities necessary for future professional activity.

We propose a language teaching method through the interaction of a trainee and a teacher in and outside the class using communicative and psychological types of pedagogical discourse and reframing the meaning. This method presupposes soft and inconspicuous speech influence introducing new values for the learner, changes in the learner's values field, the impact directly on its semantic field, the use of the effects of positive and negative emotions, joy interactions (affective component) with cognitive processes and actions; observance of stages of formation of persuasion attention, understanding, acceptance, fixation and transfer of the attitude to behavior with automation of knowledge, skills, free use of language tools. As techniques, we offer a record of students' own texts with content corresponding to those actions that help achieve the goals. For example, the problem is stated and a trainee is encouraged to create steps to solve it and use language tools depending on the person's communicative type of via mono or dialogical interaction. If the interaction is carried out orally, then the reaction of a communication participant is important. If through audio recording, then important is the pause between the basic ideas of the text. We consider the optimal pausing to be 3 seconds.

In the process of teaching a language for seniors, we recommend using more complex psychological strategies of speech interaction. On this basis, the "Advanced English Manual" and "Advanced English Guide" textbooks are built.

Let us give an example of the triple helix strategy. The technique called the "Milton Erickson Triple Spiral" is very similar to the overlapping realities technique, which is used to introduce a person into a trance state. Actually, for the same purposes it is used. The structure of technology is this: one story begins to be told, it breaks off at some point, goes to story 2 , it also breaks down, story 3 is told in full, which is embedded in suggestion (in fact, it can itself be suggestion). Then stories 2 and 1 come to an end. Human memory is arranged in such a way that by the end of the story the whole middle is forgotten, but the suggestion, if it was done correctly, remains in the subconscious. Of course, this suggestion must be made indirectly, preferably reinforced by verbal means (with some gestures, etc.). Despite the apparent complexity, the technique is very simple to use. The main thing is to know what key idea you are going to instill. In the beginning, we recommend to think or recall a story that can be used as a basis. By and large, there can be no special logical connection between the stories, but if it does, it's good and effective. As an example, let us cite a story created by one of our students:

"Nowadays more and more youngsters choose another way of meeting people - through the internet. Some of my friends found their boyfriends and girlfriends in the net - and they are absolutely happy with their choice. This made me believe that it is really possible to find a partner in this virtual reality. So I had a try. The guy I met on the ICQ seemed nice, we had some common interests and he was independent and knew what he wanted, his self-confidence attracted me most. We agreed to go out together but when we met something very unpleasant happened...

Two years ago, my parents and I went on vocation to the Black Sea. We took our cat with us. The trip was really exciting and we visited a lot of beautiful places. The kitten seemed also quite satisfied with everything happening around. It enjoyed sunbathing on the palm trees and fresh breeze. Two weeks passed quickly and on the day we were packing the things our cat refused to go with us. It climbed on a tree and didn't want to come down. We did the following: we tied one end of the rope to the tree and the other to the car, my dad moved slowly so that the tree could bend without breaking, when my mom was about to take the kitten, what do you think happened?...

Once, when I was having my teaching practice, I experienced some terrible problem - I couldn't deal with some pupils. Either they were too noisy and indulgent or aggressive and inflexible - but their attitude showed me that they didn't want to study and they wouldn't lift a finger to understand the material. Being a person with heart over mind I often blew up and it did spoil the whole impression. I couldn't handle it myself so I came to my supervisor with the problem. What she told me was really wise and I still remember how she said that word for word. She said: it is $O^{\prime} K$ to like or not to like somebody but what is essential that we must always respect people with whom we cooperate. I still hear those words and whenever I am close to crises I recollect them.

When my mom tried to take the cat from the tree, the rope broke! And the cat flew away. We were calling him and looking for him everywhere, but despite all our attempts we couldn't find him. Next year, when we came to the same place on vocation, we met an elderly woman, 
who told us that she used to be very lonely because her husband had died long ago and she had no children; she had been praying to God to send her at least somebody to entertain her last years and God heard her prayers: last summer he gave her a gift - a cat, it fell right from the sky!

I will always remember that blind date. We were enjoying ourselves and the surrounding scenery. The weather was warm, the sky was blue, the grass was green and the birds were singing. And the guy was amusing me saying funny jokes. We were sitting on a bench when I suggested to go down the hill, to enjoy the silence; guess what he said... he told me to go alone and he will wait for me here. These words pulled the trigger. I suddenly experienced a strong desire to run away from him. And I did! I went down the hill and he stayed sitting on the bench waiting for me, when he couldn't see me I changed direction and headed to the bus stop where I took a bus home. This is how the story ends."

The methodology and methods of interaction in receptive types of speech activity may differ slightly from productive ones, since the impact structure is somewhat different. Possible tricks here are: repeated key words in the pedagogical discourse, stories formed in a triple helix, when one story begins, then the second, the third and in the process of the third listeners or readers learn what the end the previous two is, thus it implements necessary ideas imperceptible to the learner.

As the language teaching practice shows, this method is very effective and allows achieving significant results both in the whole process of teaching a language and in solving an educational task in particular.

Our experience also allows us to make a method more effective using such tools for problem-solving language teaching as blogs, wikis, podcasts, social networks, virtual learning environments, electronic portfolios. Trainees acquire the skills of using on-line translators, dictionaries, encyclopedias, corps and concordances, actually teaching and Internet resources in the framework of professional activities.

Regarding bilingualism, we come to the conclusion that this term is most often understood as two languages speaking in varying degrees, the ability to use them in different capacity in various communications. The degree, scope of knowledge and skills are characterized by the readiness level for bilingual communication.

\section{Conclusion}

All recent researchers consider bilingual communicative competence as an integral system that exerts a tremendous influence on the personality development, individual abilities and knowledge, and also on the expansion of personal intercultural bonds. Researchers believe that student bilingual communicative competence can be formed only through the continuous use of the two languages as a means of educational activity, and it enhances the communicative potential, increases cognitive interest and promotes personal growth and spiritual improvement of students.
The proposed sets of tasks can be integrated into the linguistic school curricula and specialized educational institutions for bilingual students. In addition, the results of the study can be used in family education and the education of bilingual learners.

\section{References}

1. Resolution of the Government of the Russian Federation April 15, 2014 N 295 "On the approval of the state program of the Russian Federation" Development of Education "for 2013 - 2020 years." ConsultantPlus, 1992-2015. - URL: http://www.consultant.ru/document/cons_doc_LAW _ 162182/frame $=1 \mathrm{p} 30$

2. G.M. Vishnevskaya Bilingualism and its aspects (1997)

3. A.V. Timofeev Bilingual model of vocational training of the future teacher of a foreign language (2002)

4. N.E. Sorochkina Integral model of bilingual education in the modern Russian school (2000)

5. G.N. Chirsheva Features of the acquisition of vocabulary by bilingual children, 190-202 (2006)

6. V.F. Gabdulkhakov Culture and the Art of Speech (1998)

7. N.V. Kagui Multicultural education of children of preschool age in the process of bilingual education (2004)

8. Yu.D. Desheriev The development of nationalRussian bilingualism, 21-22 (1976)

9. S.G. Ter-Minasova Language and Intercultural Communication (2004)

10. V.A. Avrorin Bilingualism and School, 49-62, (1972)

11. E.V. Meshcheryakova, J.V. Meshcheryakova, E.A. Loktyushina, Russian Linguistic Bulletin, 2(6), 5-8. (2016)

12. M.S. Melnikova Designing interdisciplinary modular programs in the bilingual education system (2008)

13. Yu.L. Semenova, Bulletin of the Surgut State Pedagogical University 3(14), 68-75, (2011)

14. E.M.Safronofa, L.S. Beylinson, N.V. Zolotykh, T.U. Shevchenko, International Journal Of Environmental \& Science Education 11(16), 89688980 (2016)

15. P. Brown, S. Levinson Language Usage: Politeness Phenomena. In: E.G. Goody (ed.) Questions and Politeness: Strategies in Social Interaction (Cambridge: CUP 1978)

16. P. Brown, S.D. Levinson Politeness: Some Universals in Language Usage (Cambridge: CUP 1987)

17. E.V. Meshcheryakova, G.G. Gerkushenko, S.V. Sokolova, J.V. Meshcheryakova, $t$ World Applied Sciences Journal 24, 177 (2013) 
18. T.J. Bruneu, The Journal of Communication 23, 1746 (1973)

19. B. Fraser, Journal of Pragmatics 14(2), 219- 236 (1990).

20. S.L. Rubinstein Fundamentals of General Psychology (1988)

21. H. Colley, D. James, K. Diment, M. Tedder, Journal of Vocational Education \& Training 55(4), 471-498 (2003)

22. Roger Bennett, Journal of Vocational Education \& Training 54(4), 457-476 (2002)

23. Arminda do Paço, Maria João Palinhas, Journal of Vocational Education \& Training 63(4), 593-608 (2011)

24. A.N. Schukin Teaching Foreign Languages: Theory and Practice: A Textbook for Teachers and Students, 95-106, (2004) 